tion nor has it been published in whole or in part elsewhere. ..... I acknowledge that both I and the other authors have read the Instructions for Authors and agree with its contents." Those Instructions, in turn, state that "Submitted manuscripts must not have been published elsewhere, in whole or in part, on paper or electronically. .... The Editor-in-Chief must be notified if another manuscript derived from the same experiment has been published previously, or has been submitted to another journal." Nearly identical statements and requirements can be found in the author instructions of most journals - including the Canadian Journal of Anesthesia.

While the authors signed cover letters, first to the Canadian Journal of Anesthesia and then to Anesthesiology, attesting to their compliance with the these conditions, they did not, in fact, comply - which resulted in the publication of two very similar articles. This has now resulted in embarrassment to both Journals and to the authors. While the articles are not identical, the overlap is substantial, and if either Dr. Miller or I had been aware of the other submission, the editorial and review process would have been entirely different.

This is unfortunate and unnecessary. Editors are fully aware that it s often impossible to summarize the results of large complex studies in a single manuscript. If I had been aware of the overlap, the authors would have been given the opportunity to explain the differences in the two papers- and by working with the editorial offices, they could easily have produced a second paper addressing a distinctly different (or complementary) aspect of their study. This is something that we do on a regular basis - all it requires is that the authors be forthcoming about their other work. The result would have benefited the authors, the Journal - and our readers.

This situation should serve as a lesson to all authors. Editors take their Instructions to Authors very seriously - and so should authors. Editors are also more flexible than some might believe. There is no reason to conceal other manuscripts from us. Like authors, we want to publish the results of high-quality science (and the quality of the work being done by Nielsen, et al. is not in question). In most cases, we are happy to work with authors toward achieving a mutually beneficial result. We simply ask that authors honor their signed statements and comply fully with the well accepted "rules" established by all journals.

Michael M. Todd MD, Editor-in-Chief, Anesthesiology The University of Iowa, Department of Anesthesia, 200 Hawkins Drive, Iowa City, IA 52242-1009, USA. Phone: 319-356-4601; Fax: 319-353-6817; E-mail: anesthesiology@uiowa.edu

\section{Subtle desaturation and perioperative methemoglobinemia. The need for con- tinued vigilance}

To the Editor:

A 32-yr old $60 \mathrm{~kg}$ diabetic patient presented for exploratory laparotomy. Her past medical history included renal and pancreatic transplantation, gastroparesis, peripheral neuropathy, retinopathy, necrobiosis diabeticorum, and hypertension. She was receiving cyclosporine, prednisone, aspirin, ondansetron, dapsone, paroxetine, amitriptyline, nortriptyline, gabapentin, sirolimus, clotrimazole, metoclopramide, lansoprazole, and alendronate. Preoperative $\mathrm{SpO}_{2}$ was 92 to $96 \%$ on air. Following $i v$ clindamycin $600 \mathrm{mg}$ and midazolam $2 \mathrm{mg}$, anesthesia was induced with fentanyl $150 \mu \mathrm{g}$, lidocaine $100 \mathrm{mg}$, propofol $100 \mathrm{mg}$ and cisatracurium $10 \mathrm{mg} i$. . Her $\mathrm{SpO}_{2}$ dropped to $84-88 \%$ despite effective hand ventilation on $100 \%$ oxygen. An endotracheal tube was placed and secured at $20 \mathrm{~cm}$ to the lips. There was minimal improvement in $\mathrm{SpO}_{2}$ to $89 \%$. The oximeter probe was checked for proper placement. Breath sounds were equal with no tracheal secretions on suctioning. Fibreoptic bronchoscopy revealed no obvious obstruction. The patient's oral mucosa appeared cyanotic. Arterial blood gas sample revealed $\mathrm{pH} 7.42, \mathrm{PaCO}_{2} 29 \mathrm{mmHg}, \mathrm{PaO}_{2} 466 \mathrm{mmHg}\left(\mathrm{FIO}_{2}\right.$ $100 \%$ ), $\mathrm{BE}-5$, and $\mathrm{SaO}_{2} 91 \%$ (pulse oximeter reading $85 \%)$. Methemoglobin ( $\mathrm{MHb}$ ) was measured using a multi-wavelength spectrometer (co-oximeter), was $6.5 \%$ (normal $0.4-1.5 \%$ ). With hemodynamic stability, and improved $\mathrm{SpO}_{2}$ towards the end of surgery, methylene blue treatment was withheld. The $\mathrm{SpO}_{2}$ continued to improve in the recovery room $(91-98 \%$ on 10 $\mathrm{L} \cdot \mathrm{min}^{-1} \mathrm{O}_{2}$ ). Twelve hours after surgery, $\mathrm{MHb}$ level was $3.4 \%$. The medical records revealed a two-year treatment on dapsone for pneumocystis carinii prophylaxis, and mildly elevated $\mathrm{MHb}$ (1.9\%) during a previous anesthetic involving $60 \mathrm{mg}$ lidocaine.

This case highlights the subtle presentation of methemoglobinemia as a cause of low $\mathrm{SpO}_{2}$. Its diagnosis was established by the presence of three oxidizing

TABLE Common agents that may produce methemoglobinemia ${ }^{2}$

\begin{tabular}{lll}
\hline Aniline (dyes, inks) & Metoclopramide & Nitroprusside \\
Benzene derivatives & Methylene Blue & Phenacetin \\
Benzocaine & Nitrates & Phenol \\
Chlorates & Nitric oxide & Phenytoin \\
Chloroquine & Nitrites & Prilocaine \\
Dapsone & Nitrofurantoin & Phenytoin \\
Lidocaine & Nitroglycerin & Sulphonamides \\
\hline
\end{tabular}


agents (dapsone, metoclopramide and lidocaine) and a discrepancy between arterial oxygen saturation and pulse oximetry. ${ }^{1}$ Methemoglobinemia commonly results from exposure to oxidizing agents (Table). ${ }^{2}$ Normal levels of $\mathrm{MHb}$ are maintained by cytochrome$\mathrm{b} 5-\mathrm{MHb}$ reductase responsible for converting $\mathrm{MHb}$ to hemoglobin. ${ }^{3}$ Long-standing dapsone use probably caused elevated $\mathrm{MHb}$ levels preoperatively. Lidocaine likely added further oxidative stress causing the cytochrome-b5-MHb reductase system to be overwhelmed.

Pulse oximetry measures the ratio of absorbance of oxyhemoglobin and deoxyhemoglobin at wavelengths of $660 \mathrm{~nm}$ and $940 \mathrm{~nm}$. Because MHb absorbs light equally at both wavelengths, the light absorbance ratio of 1.0 correlates with a saturation of $85 \%$. Co-oximetry measures light absorbance at four different wavelengths and is able to distinguish $\mathrm{MHb}$ from other hemoglobins. ${ }^{4}$ A high index of suspicion is required when decreased $\mathrm{SpO}_{2}$ follows the administration of recognized oxidative agents. Patients on multiple medications are particularly prone to have their medications overlooked. Reassuringly, methemoglobinemia once diagnosed can be promptly treated.

Christina D. Noyes MD

Adeyemi J. Olufolabi MBBS DCH FRCA

Ashraf S. Habib MBBCH MSC FRCA

Duke University Medical Center, Durham, USA

E-mail: habib001@mc.duke.edu

\section{References}

1 Watcha MF, Conner MD, Hing AV. Pulse oximetry in methemoglobinemia. Am J Dis Child 1989; 143: 845-67.

2 Wright RO, Lewander WJ, Woolf AD.

Methemoglobinemia: etiology, pharmacology, and clinical management. Ann Emerg Med 1999; 34: 646-56.

3 Jaffe ER, Hultquist DE. Cytochrome b5 reductase deficiency and enzymopenic hereditary methemoglobinemia. In: Scriver CR, Beaudet AL, Sly WS, Valle D (Eds). The Metabolic and Molecular Bases of Inherited Disease, 7th ed. New York: McGraw-Hill; 1995: 3399-415.

4 Ferguson AJ, Lavery GG. Deliberate self-poisoning with dapsone. A case report and summary of relevant pharmacology and treatment. Anaesthesia 1997; 52: 359-63.

\section{A malignant hyperthermia-like reac- tion in a six-month-old female with a $5 q$ chromosomal deletion}

\section{To the Editor:}

We encountered a six-month-old female with $5 \mathrm{q}$-syndrome, who developed progressive tachycardia, hypercarbia and hyperthermia following a general anesthetic given for repair of a cleft palate. Two weeks prior, the infant had received a sevoflurane anesthetic during a magnetic resonance imaging scan of the brain. Immediately following this procedure, she experienced a self-limited episode of fever and tachycardia that were attributed to overzealous warming of the infant by the nursing staff. Body stiffness was not described. In accordance with our Human Research Protection Program, formal review and approval of this document were not required.

General anesthesia for the cleft palate repair was induced using sevoflurane and nitrous oxide, followed by neuromuscular blockade with of rocuronium 0.8 $\mathrm{mg} \cdot \mathrm{kg}^{-1} \mathrm{iv}$. Following laryngoscopy and intubation, anesthesia was maintained with isoflurane, nitrous oxide and oxygen. During the case all physiologic parameters were within normal limits. Upon completion of the repair the trachea was extubated. Vital signs on admission to the recovery room were unremarkable: heart rate 105 beats. $\mathrm{min}^{-1}$, respiratory rate 20 breaths $\cdot \mathrm{min}^{-1}$, blood pressure $96 / 40 \mathrm{mmHg}$, temperature $37^{\circ} \mathrm{C}$.

Approximately one hour later, examination revealed a heart rate of 220 beats. $\mathrm{min}^{-1}$, respiratory rate of 60 breaths. $\mathrm{min}^{-1}$, blood pressure of $126 / 62$ $\mathrm{mmHg}$, and an axillary temperature of $39.9^{\circ} \mathrm{C}$. Inspection of the child showed her to be in severe respiratory distress with hypertonia. A venous blood gas sample was obtained: $\mathrm{pH} 7.12 / \mathrm{CO}_{2} 270 / \mathrm{PO}_{2} 271$ $\mathrm{mmHg} /$ base excess -6.0. The child was intubated and cooling measures rapidly instituted. The hypermetabolic state rapidly resolved following the administration of dantrolene sodium $\left(3 \mathrm{mg} \cdot \mathrm{kg}^{-1}\right)$. The infant was admitted to the pediatric intensive care unit and subsequently received three more doses of dantrolene $\left(1 \mathrm{mg} \cdot \mathrm{kg}^{-1}\right)$. Serial laboratory examinations at 12,24 and $36 \mathrm{hr}$ revealed a peak serum creatine phosphokinase (CPK) of $260 \mathrm{IU} \cdot \mathrm{L}^{-1}$ with consistently normal serum electrolytes. She exhibited a full recovery, and was discharged from the hospital five days later, in good condition.

This is the first report of a malignant hyperthermic reaction occurring in a patient with a chromosomal deletion of $5 \mathrm{q}$. Interestingly, the infant's serum CPK 